\title{
Optimization and Models of Decalcification from Bighead Carp Scale with Citric Acid by Response Surface Method

\author{
Yu-Mei HUANG ${ }^{1, a}$, You-Qin ZOU ${ }^{2, b}$, Bo-Quan JIANG ${ }^{1,2, c^{*}}$
}

${ }^{1}$ Department of Biology and Chemistry, Institute of Science, Nanchang University College

of Science and Technology, Nanchang, Jiangxi,330029, P.R.China

${ }^{2}$ School of Resources, Environmental and Chemical Engineering Nanchang University

999 Xuefu Road, Honggu new district Nanchang, Jiangxi, 330031,P.R.China

ahymxyz@163.com, bzouyouqin@ncu.edu.cn, cijbq_win@163.com

${ }^{*}$ Corresponding author

Keywords: Bighead Crap, Fish Scale, Decalcification, Response Surface, Citric Acid.

\begin{abstract}
Fish scale is a newly developed alternative resource for extracting collagen, which is one of the important biological materials. To extract collagen from fish scale has a great significance to prevent pollution and receive good economic benefits. In this paper, based on the experimental results of single factor test, the response surface method was used to further optimize the technical parameters for the decalcification of bighead fish scale and establish the process model and kinetic model. The results showed that the maximum calcium removal rate reached $93.40 \%$ under the optimal conditions of liquid/solid ratio 23.50 , citric acid concentration $11.0 \%$, decalcification time $66.3 \mathrm{~min}$ and magnetic steering speed $989 \mathrm{r} / \mathrm{min}$ and the maximum decalcification velocity reached $241.86 \mathrm{mg} /(\mathrm{L} \cdot \mathrm{min})$ under the optimal conditions of liquid/solid ratio 10.10 , citric acid concentration $12.60 \%$, decalcification time $31.6 \mathrm{~min}$ and magnetic steering speed $865 \mathrm{r} / \mathrm{min}$. The two models in the form of multiple regression were proved to basically agree with the test values and can be used to predict the calcium removal rate and decalcification velocity under different operation parameters and the decalcification velocity corresponding to the calcium removal rate under same parameters, to adjust the operation parameters for obtaining the expected calcium removal rate and decalcification velocity, and to control the production capacity of fish scale treatment and the collagen quality prepared by following collagen extraction from the decalcified fish scale.
\end{abstract}

\section{Introduction}

The scale of fish accounts for 3\% $-5 \%$ of the fish's total weight. The protein in fish scale is about $41 \%-84 \%$ of total mass of scale. The collagen is the main ingredient in the protein. Therefore, the extraction of collagen from fish scales can not only reduce the pollution by the scales, but also obtain the cheap material in the manufacture of the collagen[1-4]. Collagen is a kind of biological macromolecule material. It plays an important organizational role in animal cells and so is one of the key raw material for the biotechnology industry and also has a huge demand in biomedical materials market. Collagen can be widely used in biomedical materials, cosmetics, food industry, research purposes, etc. In fish scale, collagen fibers are closely adhered with hydroxyapatite each other and is not easy to separate. So before extracting of collagen, the fish scale must be pretreated to remove hydroxyapatite (calcium). In recent years, many researchers have done the studies on fish scale decalcification with organic and inorganic acid as extracting agents. Most of them focused on the optimization of the process conditions. Decalcification of fish scale is a reaction between acid and salt. The process model reflects the relations between calcium removal rate (as target) and operation parameters(as influence factors). The kinetic model reflects the relations between decalcification velocity (as target) and operation parameters(as influence factors). These two models can predict and adjust the technical parameters to achieve the expected calcium removal rate and decalcification velocity under different operation conditions, which is conductive to the control 
of the production capacity of fish scale treatment and collagen quality. In this paper, based on the results of single factor test in our previous research work[5]. Response surface method with citric acid as extracting agent was used to further optimize the operation parameters and establish the process and kinetic models of decalcification from bighead fish scale and validate the models with the test values.

\section{Experiment}

\section{Raw Materials}

Bighead carp scales: collected from local market. The scales were cleaned and dried for use .

Chemicals: calcium carbonate, EDTA, citricacid, chrome black T, hydroxylamine hydrochloride, ethanol, ammonium chloride and ammonia. All the above are analytically pure.

Standard regression equation of calcium concentration

$2.7622 \mathrm{~g}$ anhydrous calcium chloride, dried to constant weight at $110^{\circ} \mathrm{C}$, was accurately weighed and added into a $500 \mathrm{~mL}$ volumetric flask to be diluted to scale.for preparing the standard calcium solution with concentration of $0.105 \mathrm{~mol} / \mathrm{L}$. Then $0.0,0.5,1.0,1.5,2.0,3.0$ and $4.0 \mathrm{~mL}$ of standard calcium solutions above were respectively added into a 150 conical flasks and diluted to $20.0 \mathrm{~mL}$ with distilled water. After that, $15 \mathrm{~mL}$ ammonia buffer $(\mathrm{pH}=10)$ and 2 drops of chrome black $\mathrm{T}$ indicator were added into the flasks. The solution was measured by titration with $0.01007 \mathrm{~mol} / \mathrm{L}$ EDTA standard solution until the color of the solution was changed from purple to blue.The consumed volume of EDTA was recorded. This measurement was conducted for two times in parallel. Then, the calcium standard curve was drawn with consumed volume of EDTA as the abscissa and calcium ion concentration as the ordinate[6]. The standard curve equation was then obtained as follows.

$$
y=-0.00976+0.02143 x
$$

\section{Measurement of calcium content}

See literature[5].

\section{Decalcification process of fish scale}

See literature [5].

\section{Measurement of calcium removal rate}

See literature [5].

\section{Measurement of decalcification velocity}

The decalcification velocity of fish scale is defined as mass of decalcified calcium per unit volume and per unit time, $\mathrm{g} /(\mathrm{L} \cdot \mathrm{min})$, which is calculated by following equation:

$$
v=\frac{x \times m_{1}}{V \times \tau} \quad(\mathrm{g} /(\mathrm{L} \cdot \min ))
$$

Where $\mathrm{V}$ is the volume of the citric acid solution, $\mathrm{mL} ; \tau$ is the time of decalcification, $\mathrm{min}$; $\mathrm{x}$ is the mass fraction in fish scale, $10,5 \%$.

\section{Establishment of Models}

The suitable operation parameters for decalcification of bighead fish scale were determined by single factor test[5]: liquid(citric acid solution)/solid(fish scales) ratio $20 \mathrm{~mL} / \mathrm{g}$, citric acid concentration $10 \%$, decalcification time $60 \mathrm{~min}$ and magnetic stirring speed $900 \mathrm{r} / \mathrm{min}$. Under the suitable conditions, the calcium removal rate reached $92.57 \%$. Based on the results of single factor test, the response surface test was carried out in this experiment. The parameters concerned above were taken as investigation factors and calcium removal rate and decalcification velocity were taken as the targets. The design of four factors with three levels was listed in Tab.1. 
Tab.1 Test design of three factors/three levels for response surface method

\begin{tabular}{llccc}
\hline \multicolumn{1}{c}{ factor } & levels & \\
& code & -1.00 & 0.00 & 1.00 \\
\hline Ratio of liquid/solid/mL/g & $\mathrm{X}_{1}$ & 15 & 20 & 25 \\
Citric acid concentration/\%(mass) & $\mathrm{X}_{2}$ & 7.5 & 10 & 12.5 \\
Decalcification time /min & $\mathrm{X}_{3}$ & 40 & 60 & 80 \\
Steering speed/r/min & $\mathrm{X}_{4}$ & 800 & 900 & 1000 \\
\hline
\end{tabular}

Tab.2 Results of response surface method

\begin{tabular}{|c|c|c|c|c|c|c|c|c|c|c|}
\hline \multirow{4}{*}{$\begin{array}{c}\text { Order } \\
\text { No. } \\
1\end{array}$} & \multirow{4}{*}{$\begin{array}{r}X_{1} \\
20\end{array}$} & \multirow{4}{*}{$\begin{array}{l}\mathrm{X}_{2} \\
10\end{array}$} & \multirow{4}{*}{$\begin{array}{r}X_{3} \\
60\end{array}$} & \multirow{4}{*}{$\begin{array}{c}\mathrm{X}_{4} \\
900\end{array}$} & \multirow{4}{*}{$\begin{array}{l}\text { Test } \\
92.57\end{array}$} & \multirow{3}{*}{\multicolumn{2}{|c|}{$\begin{array}{r}\text { calcium remov } \\
\text { Model } \\
\\
\%\end{array}$}} & \multirow{3}{*}{ Test } & \multirow{3}{*}{$\begin{array}{l}\text { decalcification } \\
\text { Model } \\
(\mathrm{L} \cdot \mathrm{min})\end{array}$} & \multirow{4}{*}{$\begin{array}{l}\text { elocity } \\
\text { relative error } \\
\% \\
0.00\end{array}$} \\
\hline & & & & & & & & & & \\
\hline & & & & & & & & & & \\
\hline & & & & & & 92.57 & 0.00 & 81.00 & 81.00 & \\
\hline 2 & 20 & 15 & 60 & 900 & 92.58 & 93.14 & 0.06 & 81.00 & 76.27 & -5.84 \\
\hline 3 & 25 & 7.5 & 80 & 800 & 89.79 & 90.64 & 0.95 & 47.14 & 44.13 & -0.023 \\
\hline 4 & 15 & 12.5 & 80 & 1000 & 90.67 & 91.23 & 0.62 & 79.34 & 77.89 & -1.83 \\
\hline 5 & 25 & 12.5 & 40 & 1000 & 90.67 & 90.91 & 0.26 & 95.29 & 101.61 & 6.63 \\
\hline 6 & 15 & 7.5 & 80 & 1000 & 88.81 & 89.50 & 0.78 & 77.71 & 76.33 & -1.78 \\
\hline 7 & 20 & 10 & 60 & 700 & 91.67 & 90.33 & $-1.46^{*}$ & 80.21 & 74.78 & $-6.77^{*}$ \\
\hline 8 & 20 & 10 & 60 & 900 & 92.57 & 92.57 & 0.00 & 81.00 & 81.00 & 0.00 \\
\hline 9 & 25 & 7.5 & 40 & 1000 & 88.82 & 89.03 & 0.24 & 93.26 & 99.70 & 6.91 \\
\hline 10 & 15 & 7.5 & 40 & 1000 & 86.99 & 87.35 & 0.41 & 152.23 & 160.70 & 5.56 \\
\hline 11 & 25 & 12.5 & 80 & 1000 & 92.58 & 91.80 & -0.84 & 48.60 & 44.98 & -7.45 \\
\hline 12 & 15 & 12.5 & 40 & 800 & 87.95 & 88.31 & 0.40 & 153.91 & 162.24 & 5.41 \\
\hline 13 & 15 & 12.5 & 80 & 800 & 89.79 & 90.48 & 0.77 & 78.57 & 77.21 & -1.73 \\
\hline 14 & 20 & 5 & 60 & 900 & 89.72 & 88.37 & $-1.50^{*}$ & 78.51 & 72.94 & $-7.09^{*}$ \\
\hline 15 & 25 & 12.5 & 40 & 800 & 89.80 & 90.17 & 0.41 & 94.29 & 100.75 & 6.85 \\
\hline 16 & 25 & 7.5 & 40 & 800 & 87.96 & 88.47 & 0.58 & 92.36 & 98.88 & 7.06 \\
\hline 17 & 25 & 7.5 & 80 & 1000 & 90.66 & 91.37 & 0.78 & 47.60 & 44.34 & -6.85 \\
\hline 18 & 25 & 12.5 & 80 & 800 & 91.68 & 92.39 & 0.77 & 48.13 & 44.73 & -7.06 \\
\hline 19 & 20 & 10 & 60 & 900 & 92.57 & 92.57 & 0.00 & 81.00 & 81.00 & 0.00 \\
\hline 20 & 15 & 7.5 & 40 & 800 & 86.15 & 86.65 & 0.58 & 150.76 & 159.46 & 5.77 \\
\hline 21 & 20 & 10 & 60 & 900 & 92.57 & 92.57 & 0.00 & 81.00 & 81.00 & 0.00 \\
\hline 22 & 20 & 10 & 60 & 900 & 92.57 & 92.57 & 0.00 & 81.00 & 81.00 & 0.00 \\
\hline 23 & 20 & 10 & 60 & 900 & 92.57 & 92.57 & 0.00 & 81.00 & 81.00 & 0.00 \\
\hline 24 & 10 & 10 & 60 & 900 & 88.77 & 87.73 & $-1.17^{*}$ & 155.35 & 146.34 & $-5.80^{*}$ \\
\hline 25 & 20 & 10 & 60 & 1100 & 92.58 & 90.84 & $-1.88^{*}$ & 81.00 & 76.39 & $-5.69^{*}$ \\
\hline 26 & 20 & 10 & 20 & 900 & 86.87 & 86.48 & $-0.45^{*}$ & 228.03 & 203.44 & $-10.78^{*}$ \\
\hline 27 & 20 & 10 & 100 & 900 & 92.58 & 91.79 & $-0.85^{*}$ & 48.60 & 63.04 & $29.71^{*}$ \\
\hline 28 & 15 & 7.5 & 80 & 800 & 87.94 & 88.77 & 0.94 & 76.95 & 75.70 & -1.62 \\
\hline 29 & 30 & 10 & 60 & 900 & 92.56 & 91.47 & $-1.07^{*}$ & 54.00 & 52.85 & $-2.13^{*}$ \\
\hline 30 & 15 & 12.5 & 40 & 1000 & 88.82 & 89.19 & 0.42 & 155.44 & 163.53 & 5.20 \\
\hline
\end{tabular}


According to the design above, 30 sets of test (including 5 sets of central group tests) were separately conducted when the calcium removal rate and decalcification velocity were taken as targets and the results were listed in Tab.2.

The results of variance analysis of regression model with calcium removal rate and decalcification velocity as targets were exhibited in Tab.3 and Tab.4, respectively.

Tab.3 Result of variance analysis of regression model ( with calcium removal rate as target)

\begin{tabular}{|c|c|c|c|c|c|c|}
\hline Source & Sum of square & $\begin{array}{c}\text { Degree of freedom } \\
\text { DF }\end{array}$ & $\begin{array}{c}\text { Mean square } \\
\text { MS }\end{array}$ & $\mathrm{F}$ value & Prob $>F$ & Significance level \\
\hline model & 111.83 & 14 & 7.99 & 7.75 & 0.0002 & significant \\
\hline $\mathrm{X}_{1}$ & 20.94 & 1 & 20.94 & 20.31 & 0.0004 & \\
\hline $\mathrm{X}_{2}$ & 17.61 & 1 & 17.61 & 17.08 & 0.0009 & \\
\hline $\mathrm{X}_{3}$ & 28.56 & 1 & 28.56 & 27.70 & $<0.0001$ & \\
\hline $\mathrm{X}_{4}$ & 3.21 & 1 & 3.21 & 3.12 & 0.0979 & \\
\hline $\mathrm{X}_{1} \mathrm{X}_{2}$ & $1.600 \times 10^{-3}$ & 1 & $1.600 \times 10^{-3}$ & $1.552 \times 10^{-3}$ & 0.9691 & \\
\hline $\mathrm{X}_{1} \mathrm{X}_{3}$ & $1.600 \times 10^{-3}$ & 1 & $1.600 \times 10^{-3}$ & $1.552 \times 10^{-3}$ & 0.9691 & \\
\hline $\mathrm{X}_{1} \mathrm{X}_{4}$ & $1.000 \times 10^{-4}$ & 1 & $1.000 \times 10^{-4}$ & $9.699 \times 10^{-5}$ & 0.9923 & \\
\hline $\mathrm{X}_{2} \mathrm{X}_{3}$ & $2.500 \times 10^{-3}$ & 1 & $2.500 \times 10^{-3}$ & $2.452 \times 10^{-3}$ & 0.9614 & \\
\hline $\mathrm{X}_{2} \mathrm{X}_{4}$ & $4.000 \times 10^{-4}$ & 1 & $4.000 \times 10^{-4}$ & $3.880 \times 10^{-4}$ & 0.9845 & \\
\hline$X^{3} X_{4}$ & $4.000 \times 10^{-4}$ & 1 & $4.000 \times 10^{-4}$ & $3.880 \times 10^{-4}$ & 0.9845 & \\
\hline $\mathrm{X}_{1}^{2}$ & 15.13 & 1 & 15.13 & 14.68 & 0.0016 & \\
\hline $\mathrm{X}_{2}^{2}$ & 10.59 & 1 & 10.59 & 10.27 & 0.0059 & \\
\hline $\mathrm{X}_{3}^{2}$ & 26.22 & 1 & 26.22 & 25.43 & 0.0001 & \\
\hline $\mathrm{X}_{4}^{2}$ & 3.91 & 1 & 3.91 & 3.80 & 0.0704 & \\
\hline Residual & 15.46 & 15 & 1.03 & & & \\
\hline Lack of Fit & 15.46 & 10 & 1.55 & & & Not significant \\
\hline Pure error & 0.000 & 5 & 0.000 & & & \\
\hline Total variation & 127.30 & 29 & & & & \\
\hline $\mathrm{R}^{2}$ & 0.8785 & & & & & \\
\hline
\end{tabular}

The Design-expert 7.0 software was used to make the multiple regression fitting of the data in Tab.2 to obtain the multiple regression models as below. The model (3)with calcium removal rate as target reflects the relations between calcium removal rate and factors of ratio of liquid/solid $\left(\mathrm{X}_{1}\right)$, citric acid concentration $\left(\mathrm{X}_{2}\right)$, decalcification time $\left(\mathrm{X}_{3}\right)$ and steering speed $\left(\mathrm{X}_{4}\right)$. The model (4)with decalcification velocity as target reflects the relations between decalcification velocity and factors of ratio of liquid/solid $\left(\mathrm{X}_{1}\right)$, citric acid concentration $\left(\mathrm{X}_{2}\right)$, decalcification time $\left(\mathrm{X}_{3}\right)$ and steering speed $\left(\mathrm{X}_{4}\right)$.

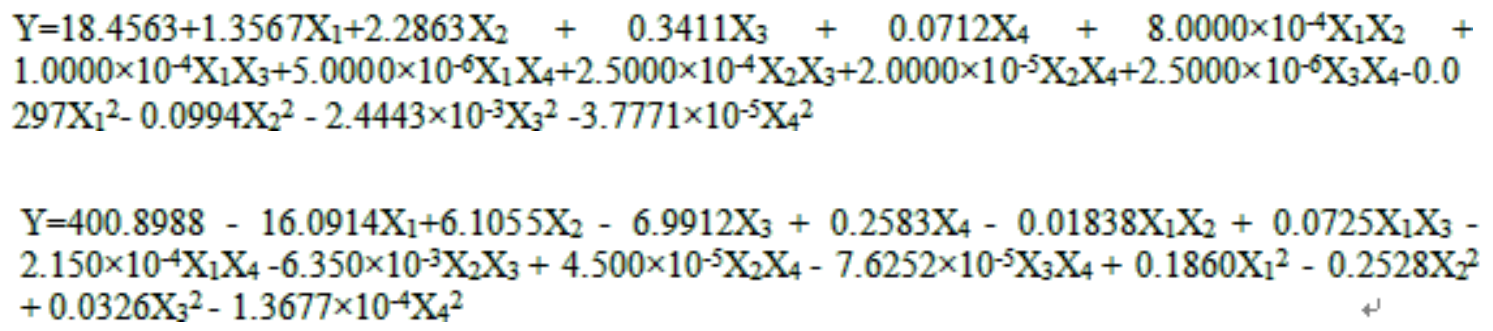


Tab.4 Results of variance analysis of regression model (with decalcification velocity as target)

\begin{tabular}{|c|c|c|c|c|c|c|}
\hline Source & Sum of square & $\begin{array}{c}\text { Degree of freedom } \\
\text { DF }\end{array}$ & $\begin{array}{c}\text { Mean square } \\
\text { MS }\end{array}$ & $\mathrm{F}$ value & Prob $>F$ & Significance level \\
\hline model & 49133.68 & 14 & 3509.55 & 35.11 & $<0.0001$ & significant \\
\hline $\mathrm{X}_{1}$ & 13110.57 & 1 & 13110.57 & 131.15 & $<0.0001$ & \\
\hline $\mathrm{X}_{2}$ & 17.58 & 1 & 17.58 & 0.18 & 0.6809 & \\
\hline $\mathrm{X}_{3}$ & 29565.43 & 1 & 29565.43 & 295.75 & $<0.0001$ & \\
\hline $\mathrm{X}_{4}$ & 3.33 & 1 & 3.33 & 0.033 & 0.8576 & \\
\hline $\mathrm{X}_{1} \mathrm{X}_{2}$ & 0.84 & 1 & $0.84^{3}$ & $8.375 \times 10^{-3}$ & 0.9283 & \\
\hline $\mathrm{X}_{1} \mathrm{X}_{3}$ & 841.58 & 1 & 841.58 & 8.42 & 0.0110 & \\
\hline $\mathrm{X}_{1} \mathrm{X}_{4}$ & 0.18 & 1 & 0.18 & $1.807 \times 10^{-3}$ & 0.9667 & \\
\hline $\mathrm{X}_{2} \mathrm{X}_{3}$ & 1.61 & 1 & 1.61 & 0.016 & 0.9006 & \\
\hline $\mathrm{X}_{2} \mathrm{X}_{4}$ & $2.025 \times 10^{-3}$ & 1 & $2.025 \times 10^{-3}$ & $2.026 \times 10^{-5}$ & 0.9965 & \\
\hline $\mathrm{X}_{3} \mathrm{X}_{4}$ & 0.37 & 1 & 0.37 & $3.722 \times 10^{-3}$ & 0.9522 & \\
\hline $\mathrm{X}_{1}^{2}$ & 593.02 & 1 & 593.02 & 5.93 & 0.0278 & \\
\hline $\mathrm{X}_{2}^{2}$ & 68.49 & 1 & 68.49 & 0.69 & 0.4208 & \\
\hline $\mathrm{X}_{3}^{2}$ & 4678.17 & 1 & 4678.17 & 46.80 & $<0.0001$ & \\
\hline $\mathrm{X}_{4}^{2}$ & 51.31 & 1 & 51.31 & 0.51 & 0.4847 & \\
\hline Residual & 1499.52 & 15 & 99.97 & & & \\
\hline Lack of Fit & 1499.52 & 10 & 149.95 & & & Not significant \\
\hline Pure error & 0.000 & 5 & 0.000 & & & \\
\hline Total variation & 50633.20 & 29 & & & & \\
\hline $\mathrm{R}^{2}$ & 09704 & & & & & \\
\hline
\end{tabular}

It is known from Table 3 that the model F-value of 7.751 implies the model is significant. There is only a $0.02 \%$ chance that "a Model F-value"this large could occur due to noise. The values of "Prob $>F^{\prime}$ " less than 0.0500 indicate the model terms are significant, in this case, $\mathrm{X}_{1}, \mathrm{X}_{2}, \mathrm{X}_{3}, \mathrm{X}_{1}{ }^{2}, \mathrm{X}_{2}^{2}$ and $\mathrm{X}_{3}{ }^{2}$ are significant model terms. The values of " Prob $>F$ " greater than 0.1000 indicate the model terms are not significant, in this case, $\mathrm{X}_{4}, \mathrm{X}_{1} \mathrm{X}_{2}, \mathrm{X}_{1} \mathrm{X}_{3}, \mathrm{X}_{1} \mathrm{X}_{4}, \mathrm{X}_{2} \mathrm{X}_{3}, \mathrm{X}_{2} \mathrm{X}_{4}, \mathrm{X}_{3} \mathrm{X}_{4}$ and $\mathrm{X}_{4}^{2} \mathrm{X}_{2} \mathrm{X}_{3}$ are not significant model terms. The correlation coefficient of the model is $R^{2}=0.8785$, which means that the model can basically describe the test results and only $12.15 \%$ of total variation of response value cannot be explained by the model. Furthermore, as shown in the $8^{\text {th }}$ column of "relative error" of Table 2, the actual test values of calcium removal rate are close to those of the model and their relative errors are ranged from $0.00 \%$ to $0.95 \%$ (absolute values)within the value range which was taken in the response surface experiment except the values marked with "**, indicating that the model is accurate and can be used to predict and adjust the process parameters for obtaining the expected calcium removal rate. According to the "Prob $>F$ " values of $\mathrm{X}_{1}, \mathrm{X}_{2}, \mathrm{X}_{3}$ and $\mathrm{X}_{4}$ in Table 3 , the significance of the effects of the four factors on the calcium removal rate can be determined to be $X_{3}>X_{1}>X_{2}>X_{4}$. The technical parameters were further optimized to be liquid/solid ratio 23.50, citric acid concentration $11.0 \%$, decalcification time $66.3 \mathrm{~min}$ and steering speed $989 \mathrm{r} / \mathrm{min}$ by the solution of the model (3) with the software. Under the optimal conditions, the maximum calcium removal rate was $93.40 \%$.

It is known from Table 4 that the model F-value of 35.11 implies the model is significant. There is only less than $0.01 \%$ chance that "a Model F-value" this large could occur due to noise. The values of "Prob $>F$ " less than 0.0500 indicate the model terms are significant, in this case, $\mathrm{X}_{1}, \mathrm{X}_{3}$, $\mathrm{X}_{1} \mathrm{X}_{3}, \mathrm{X}_{1}{ }^{2}$ and $\mathrm{X}_{3}{ }^{2}$ are significant model terms. The values of "Prob $>F$ " greater than 0.1000 
indicate the model terms are not significant, in this case, $\mathrm{X}_{2}, \mathrm{X}_{4}, \mathrm{X}_{1} \mathrm{X}_{2}, \mathrm{X}_{1} \mathrm{X}_{4}, \mathrm{X}_{2} \mathrm{X}_{3}, \mathrm{X}_{2} \mathrm{X}_{4}, \mathrm{X}_{3} \mathrm{X}_{4}, \mathrm{X}_{2}^{2}$, and $\mathrm{X}_{4}{ }^{2}$ are not significant model terms. The model " Prob $>F$ " value less than 0.0001 indicate that the relations between the response value (decalcification velocity) and the four factors are extremely significant and the test results are reliable..The correlation coefficient of the model is $\mathrm{R}^{2}=0.9704$, which means that the model can well describe the test results and only about $3.0 \%$ of total variation of response value cannot be explained by the model. Furthermore, as shown in the $11^{\text {th }}$ column of "relative error" of Table 2 , the actual test values of decalcification velocity are basically close to those of the model and their relative errors are ranged from $0.00 \%$ to $7.457 \%$ (absolute values) within the value range which was taken in the response surface experiment except the values marked with "*”, indicating that the model is basically agreed with the practical values and can be used to predict and adjust the process parameters for obtaining the expected decalcification velocity.According to the "Prob $>F$ " values of $\mathrm{X}_{1}, \mathrm{X}_{2}, \mathrm{X}_{3}$ and $\mathrm{X}_{4}$ in Table 4 , the significance of the effects of the four factors on the decalcification velocity can be determined to be $X_{3}>X_{1}>X_{2}>X_{4}$, which is same as those for the target of calcium removal rate. The technical parameters were further optimized to be liquid/solid ratio 10.10 , citric acid concentration $12.60 \%$, decalcification time 31.6 min and steering speed $865 \mathrm{r} / \mathrm{min}$ by the solution of the model (4) with the software. Under the optimal conditions, the maximum decalcification velocity was $241.86 \mathrm{mg} /(\mathrm{L} \cdot \mathrm{min})$.

\section{Conclusions}

The technical parameters were further optimized by response surface method.The optimal parameters were determined to be liquid/solid ratio 23.50 , citric acid concentration $11.0 \%$, decalcification time $66.3 \mathrm{~min}$ and steering speed $989 \mathrm{r} / \mathrm{min}$ under which the maximum calcium removal rate was $93.40 \%$ and liquid/solid ratio 10.10 , citric acid concentration $12.60 \%$, decalcification time $31.6 \mathrm{~min}$ and steering speed $865 \mathrm{r} / \mathrm{min}$, under which the maximum decalcification velocity reached $0.4932 \mathrm{~g} /(\mathrm{L} \cdot \mathrm{min})$. The models in the form of multiple regression were basically in agreement with the test values. They can be applied to predict the calcium removal rate and decalcification velocity under different operation conditions and the decalcification velocity corresponding to the calcium removal rate under same conditions in order to adjust the operation parameters for gaining the expected calcium removal rate and decalcification velocity and to control the production capacity of fish scale treatment and the collagen quality and collagen production output in the following collagen extraction from the decalcified fish scale.

\section{Acknowledgements}

This research was financially supported by Jiangxi province as a key project in achievements in science and technology (No. 20124ABE02104).This research was financially supported by the national natural science funds projects of China (No. 21367021).

\section{References}

[1]Yu-Ru Huang, Chyuan-Yuan Shiao, Hui-Huang Chen, et al: Food Hydrocolloids 25 (2011), p. 1507.

[2]He Li, Bailing Liu, Hualin Chen: China Leather 31 (2012), p.14.

[3]Kanokwan, Matmaaroh, Soottawat Benjakul, et al: Food Chemistry 129 (2011), p. 1179.

[4]Dasong Liu, Li Liang, Joe M., Regenstein, Pen: Food Chemistry 133(2012), p.1441.

[5]Jiang Boquan, Zeng Jiangnan, Zeng Qingfang, etc:. Journal of Nanchang University (Engineering \& Technology), 35(2013), p.252.

[6]Ning Zhengxiang. Food composition analysis manual [M]. Beijing: China, Light Industry Press, 1998:579-583. 